\title{
The ethics of mobility: a framework for assessing mobility paradigms
}

\author{
T. Shannon \\ School of Global Studies, Social Science and Planning, \\ RMIT University, Australia
}

\begin{abstract}
Given the recognised adverse effects of automobility, there is a strong need for a normative assessment framework capable of evaluating the desirability of mobility arrangements, including transport infrastructure and its supportive urban form. The existing decision-making framework, based on technical models, does not incorporate an analysis of what mobility ought to achieve. By adopting the rationale used by moral philosophers, it is possible to construct a framework of norms based on the ends that mobility should achieve. Mobility should produce positive and equitably distributed benefits not just economically, but also environmentally and socially.
\end{abstract}

Keywords: mobility, ethics, automobility, sprawl, reflexive mobility, norms.

\section{Introduction}

In the ancient Islamic city of Kano in northern Nigeria, government officials are banning women from riding on motorcycle taxis, whose drivers may 'press their bodies close'. Women's public transport options will be reduced to public minibuses. The policy is an effort to enforce the strict Islamic legal code [1], and is therefore an example where an ethical issue relating to mobility has been identified and acted upon with the assistance of a moral framework. The rationale is simple: the objective is to reduce contact between men and women while travelling, and the chosen solution is to control women's mobility choices.

Ethics, or moral philosophy, is the junction where philosophy combines values and practical issues, thereby providing a major part of the practical justification for philosophy [2]. A 'moral' or 'ethic' is a behavioural expectation that arises from our notions of what is right and wrong, and therefore provides a 
guideline or norm for putting that belief into practice [3]. Ethics is the branch of philosophy that guides decisions and choices, and as such is of particular relevance to the decision-making process. Ethics, politics and planning all deal with choices, and are therefore concerned with the identification of proper ends and the appropriate means by which to achieve them [4].

Unlike Nigeria, in the west we do not have a strict moral code for guidance, and so a different ethical framework is required if decision-makers are to apply ethics to transport issues. Because we do not uniformly subscribe to one ethical framework, ethical issues in a secular society are difficult to identify, and their solutions difficult to agree upon. Ethical norms remain hidden and unchallenged within technical frameworks that appear to be value-neutral. Yet politicians and the professionals that provide information to guide their choices, including planners and engineers, are moral agents - the planner is not simply a bureaucrat or mere technical functionary, he or she is an active participant in the identification of and movement toward that which is considered good [5].

A few scholars have examined the association between transport issues and ethics, most notably the negative consequences of automobility, and the reasons why this paradigm continues to dominate urban development. However, as yet there is no established theory available to form the basis of a transport-focused ethical framework:

Three problems can be identified in this regard. First, within philosophical inquiry, transport issues have been largely ignored, because it was felt that transport ethics had no scholarly traditions to lean on. Second, within the camp of transportation researchers, it is a major challenge to explain to engineers and economists the place of ethics in the overall transportation picture. And third, the general public is not interested in listening to the adverse effects of transport, because of the taken-for-granted success of the automobile. These three problems are deeply intertwined. [6]

This aim of this paper is to introduce a conceptual framework for transport ethics. First, however, it is necessary to understand the phenomenon of automobile dependence as a paradigm and why it prevails despite heavy criticism of its environmental and social impacts. From this analysis, it becomes clear that a normative approach is needed if decisions that affect mobility outcomes are to contribute towards the achievement of a sustainable mobility paradigm.

\section{Automobility: the modern mobility paradigm}

'Transport' refers to movement between destinations, and therefore encompasses issues of how, when, and why movement between A and B occurs, but not issues to do with the accessibility of A and B. 'Mobility' has been defined as: "the ease with which destinations can be reached" [7], and is therefore concerned with potential as well as actual movement. Furthermore, mobility has also been 
defined as a policy concept, being "infused with meanings, aspirations and potentials" and having "transformed modern culture in its own image" [8]. Mobility outcomes are not merely accidental, they are created by policies and cultural understandings; mobility is paradigmatic.

Given the prevalence of the automobile in most industrialised countries, and the growing use of automobiles in industrialising countries, the automobile is undoubtedly the basis of the modern mobility paradigm. The term 'automobility' is increasingly used to describe this paradigm, however just as mobility is not just about actual movement, automobility describes not only our dependence on cars, but the various constructs that support it, such as urban form, infrastructure provision, and policy concepts, i.e.; those things that produce the spatiotemporalities that provide the potential for automobiles to move from A to B. These spatiotemporalities encourage the development and reproduction of the paradigm in a process of 'automobilisation'.

Automobility refers therefore not only to cars, but to the infrastructure, policies and urban form that support their use and manufacture. Typically, automobility is supported not only by roads and freeways, but by a particular urban form, and the policies that support this type of development. Urban sprawl is the generic name given to low-density, highly segregated land use. Whilst understandings of what sprawl is - i.e. whether it is organised or unorganised sprawl - differ, it is the basic spatial elements of sprawl that support automobility, and therefore it is these elements I am referring to when I discuss sprawl.

The correlations between automobility and sprawl have been discussed by several authors [9-12], most notably Newman and Kenworthy, who discovered a strong relationship between low density urban form, automobile use, and pollution. The negative effects of both sprawl and automobility have also been the subject of much discussion:

There are many other pollutants and problems, such as noise pollution, the economic costs of congestion, deaths and injuries to road users and pedestrians, the ruination of urban environments and agricultural and countryside land loss associated with urban sprawl. The approximate contribution of road transport to environmental problems has been estimated as: climate change, $20 \%$; acidification, $20 \%$; smog, $70 \%$; lead pollution, $50-85 \%$; nuisance, $60 \%$ and waste, $5 \%$. [13]

Automobility and sprawl have not only been identified as a cause of environmental pollution and ecological disruption, but also as a cause of social and health problems, including lung cancers and asthma from air pollution [14], obesity and overweight $[15,16]$, and depression as a result of traffic stress [17]. Furthermore, transport disadvantage - the inability to travel when and where one needs without difficulty - is a potential precursor to unemployment, personal and family stress, ill-health and personal crisis [7]. 
The adverse consequences of automobility are not always overlooked. However, congestion and road safety issues appear to be the only consequences taken seriously in many cities, with increased road capacity being the prevailing solution to these problems. Such solutions further reinforce automobilisation and therefore do not serve to reduce but rather to increase the problems associated with automobility: "Instead of fostering the rise of a different, post-automotive mobility paradigm, their responses often merely lead to a reproduction of traditional 'auto-spaces' [18].

\section{Reflexive mobility}

Automobility is currently reflexive to the extent that problems are often identified and acted upon, however this reflexivity has not created sufficient space for the emergence of other mobility paradigms. The natural scientific approach, whereby we attempt only to understand what is rather than what ought to be, could be largely responsible for such a blinkered, intra-paradigmatic approach. The economic and engineering foundations of transport planning certainly do not encourage reflexivity. For instance, if we predict travel demands by mode based on existing patterns (an analysis of what $i s$ ), and allocate future infrastructure and services accordingly (with no analysis of what ought to be), we imply that these conditions are acceptable [19]. The 'measure it, predict it, build it' approach is purely technical and does not provide the foundation of a truly reflexive analysis of mobility.

Low and Gleeson [20] have discussed the value systems and habits embedded in our institutions and rules, in an attempt to explain the barriers to achieving sustainability in transportation planning. They blame the utopian and impossible aim of free-flowing traffic designed to reduce congestion costs and increase economic benefit. Aggregate economic benefit and freedom of movement are the modern goals of mobility. But these objectives are not final ends. Freedom of movement must exist to satisfy some other objective, as must wealth.

The belief that transport is a pre-condition for economic growth leads to the dismissal of sustainable transport research at a political level, for fear that the regulation or reduction of transport to improve sustainability is a threat to the economy [21]. Evidence of the economic equity benefits of public transport seems to be ignored by decision-makers in automobile dependent cities. Perhaps it is Bachman's Inevitability Theorem in action; the higher the cost of implementing the plan, the less likely the plan will be abandoned even when it becomes obvious that it is not a good plan. Each mode of transportation is supported by structures, cultures, constituencies and interest groups that benefit from a modal focus [22].

Mobility should be questioned at a deeper, ought to be level, rather than at a shallow what is level. What is required is a normative framework that specifies mobility objectives and enables the integration of moral information. The example of Kano in Northern Nigeria illustrates how a normative framework can provide a set of objectives for mobility outcomes. However, rather than adopting a religious moral code, we require a rationally defensible normative 
framework that enables decision-makers to deal objectively with the consequences of automobility. We need a framework that puts our mobility objectives into perspective, framing the ideals of unlimited freedom and car ownership, and the profits car manufacturers and their employees, in perspective against environmental, cultural and social considerations. Normative ethics provides an appropriate rationale for constructing a set of norms that can be applied to mobility.

\section{Normative ethics}

A normative approach may be defined as one which posits one or more moral precepts possessing at least formal (if not some contentful) meaning by which human actions ought to be controlled. [23]

Ethics has two components, meta-ethics and normative ethics. Meta-ethics is the study of ethics itself, rather than the application of standards and guidelines to behaviour, as in normative ethics [24]. Normative ethics is therefore the branch of ethics most relevant to decision-making. Normative ethics can be challenging, given we tend to think of science as a way to describe and understand the way things are, rather than the way things ought to be.

Contemporary secular ethics acknowledges that different cultures and societies subscribe to different moral frameworks, and that moral frameworks evolve over time. Such evolution does not necessarily negate that ethics are absolute (that there is only one correct set of ethical principles). In fact, there are some moral beliefs about which almost all societies are in agreement, however this does not imply that they are correct [24]. If six billion people believe a foolish thing, it is still a foolish thing.

\subsection{Constructing rational norms}

Artistotle was of the view that all knowledge and every pursuit aims at some particular end. His method of analysis was therefore to reflect on the end being sought; "In medicine this is health, in strategy victory, in architecture a house, in any other sphere something else" [25]. An end is that which is always desirable, not for the sake of something else. The first task of normative ethics is to ask what qualifies as an end. Ethics theory provides several distinct possibilities. First, there is the utilitarian view that some form of desirable consciousness is the end we seek, whether this is conceived as the 'ceasing of woe' as it was by The Buddha, happiness as in Aristotle's philosophy, or pleasure in the Epicurean philosophy.

The natural law tradition claims we each have within our own nature an inherent guide to what is good, whereas John Locke believed rights exist in a state of nature, and are retained outside of a state of nature, including cities. These approaches are deontological; they focus on intrinsic goods, knowable rather than analytically constructed. The alternative approach is teleological, 
whereby ethical analysis aims to assess the ends or results of actions (telos: end or purpose). A teleological approach does not rely upon intuition, and can therefore provide a rationally justified, analytical framework. One drawback is that a teleological approach is not necessarily normative. A normative ethic is prescriptive rather than merely descriptive, it commands certain courses of action [23]. Without obtaining further information about how to achieve a desired end, a teleological approach is merely descriptive, therefore it must also be empirical if it is to be normative.

Utilitarians appeal to the 'fund' of human experience to determine which action will bring about the greatest good, drawing from experience of what has been found to work. Therefore, the teleological approach is concerned with standards (through achieving ends), rather than rules based on intrinsic goods or rights. By appealing to the fund of experience, the teleological approach creates norms. For example, if human health is considered an important end of mobility, and experience demonstrates that automobile dependence has significant adverse health effects, whereas walking produces positive health effects, the ethical solution is to encourage walking over driving.

\subsection{An aggregative/distributive approach}

Utilitarianism is flawed in that its approach is purely aggregative, an action is right if it produces a large net amount of a desirable good. A mobility ethic requires guidance not only as to what constitutes a desirable end, but also as to its proper distribution. This is perhaps a more difficult objective. "Intelligence is the ability to increase efficiency: wisdom is the ability to increase effectiveness" [6]. Mobility has important equity implications; the distribution of accessible destinations, travel costs, transport options, health and social impacts often differ by location and socio-economic status [26].

John Rawls' theory of justice, 'justice as fairness', provides a method of incorporating the proper distribution of goods (justice) into a teleological (outcomes based) ethic [27]. Using a contract ethics approach, Rawls reasons that in an initial, hypothetical position of equality between persons who do not know their relative positions of wealth in society, the principles of justice would be agreed upon. Thus, inequalities can only be just if they result in compensating benefits for all. By considering justice a desired end in itself, goods must be equitably distributed if their existence is to be considered morally acceptable. Justice as fairness counters the foremost criticism of utilitarianism; that issues of justice are ignored. Rawls' philosophy provides an approach that is not only aggregative, but also distributive; where both the production of net value and its distribution are important in measuring the attainment of an end.

\subsection{Ends and their relative importance}

Within the modern western context, there is some consensus regarding ends [3]. One could assume that there would also be some consensus on the ends that urban development and transport policies should pursue. Although differences may assert themselves in practice, this does not necessarily indicate differences 
with regard to ends, instead there may only be differences in the approach adopted to satisfy these ends [28]. With no consensus regarding ends, let alone any means of providing relative weights to these ends, how do we decide which ends are desirable and therefore good? The utilitarian approach is flawed in this respect, as it must rely upon intuitionism in order to provide a weighting to ends.

Some criteria are therefore required to identify desired ends and decide upon their relative importance, before we are able to measure their attainment and decide whether or not mobility has achieved an ethical outcome.

\section{The ethics of enough}

Sustainability theory provides a starting point for identifying ends and weighting them. The three pillars of sustainability represent the environmental, economic and social considerations that form the basis of sustainable development. The challenge is to find development solutions conducive to all pillars, so that one does not compromise the other. Typically it is the economic realm that is given greater priority over the others, leading to damaging environmental and social consequences. Applying the three pillars framework to mobility ethics may provide a way to reduce dilemmas by insisting on win-win solutions.

The 'ethics of enough' provides a logical and straightforward conceptual model, organising ends within the context of sustainability. This conceptual framework is underpinned by two basic premises. First, we need a modicum of wealth to make life worthwhile. This wealth is not necessarily money but simply good fortune, or quality of life. Second, we ought to require needs before wants, or our wants will be met at the expense of our basic needs.

Needs are what we desire, or ought to desire, for they are good for us - we really need them. They in turn can be categorised as:

1. Primary needs. These are food, water, shelter, clothing, and health. We need these for our very survival as individual organisms. At a pinch we can provide these ourselves but rarely do so in isolation.

2. Secondary needs. These are love, relationships, freedom, education, safety, other material resources and wealth. We need these for living, to make life enjoyable and provide meaning. We cannot provide these needs ourselves, we need others.

Wants are all our other desires. They can be right and wrong desires and can be categorised as:

- Innocuous wants. These do not prevent or impede us or others attaining our or their needs. To which we should add, provided they do not reduce the capacity of the earth to sustain us and inspire us.

- Noxious wants. These displace or attenuate our desires for needs, particularly secondary needs. Furthermore, they reduce the capacity of the earth to sustain and inspire us. [29] 
While this is an anthropocentric approach, it is obvious that human needs are less compromising to natural systems compared with noxious wants. Both affluence and extreme poverty have adverse environmental effects. Combining the ethics of enough with an aggregative/distributive approach provides a framework for weighting ends, and incorporates a strong notion of justice.

The value placed upon unlimited personal freedom makes cars particularly attractive. The association between road building and economic growth makes automobility attractive to decision-makers concerned with economic development. If these decision-makers were required to put aggregate economic development into context against other ends, and to look also at equity issues, the outcome would very likely be different.

\section{Conclusion: mobility ethics}

The logical-positivist position is that ethical questions are not resolvable. However, our continued reliance upon the technical, what is approach will result in further entrenchment of the dominant mobility paradigm. Philosophers now recognise that ethical reasoning is not unlike scientific reasoning [30]. If rationally defensible criteria are applied to the evaluation of ethical positions, ethical discourse could be accepted as a rational activity. A rational framework for the evaluation of mobility issues, or mobility paradigms generally, would provide an important normative decision-making tool that is truly reflexive, thereby enabling reform.

Some authors have questioned the dominant mobility paradigm, for example John Urry has asked whether the time-space demands of automobility should be allowed to dominate the urban realm [31]. This can be re-written: 'What ends should mobility achieve, and does the domination of the automobile over the urban realm reasonably meet these criteria in regard to the aggregate achievement of these ends and their equitable distribution?' If the domination of automobility over the urban realm does not provide an ideal means to our chosen ends, or results in their unjust distribution, the fund of experience can be consulted in search of a more conducive solution. The first ends to be considered should be needs, and noxious wants should also be identified so they can be avoided. By following this rationale, a sustainable and socially just mobility paradigm can be discovered and implemented.

Further investigation is required to develop this framework so that an ethical analysis of automobility can be undertaken. First, needs, wants and noxious wants relevant to mobility must be identified. Second, indicators need to be developed based on these needs and wants, so that empirical information can be gathered. Third, existing empirical evidence relating to automobility and alternative paradigms (the fund of experience) should be reviewed so that initial comparisons between mobility paradigms can be made. Finally, using these indicators, further empirical research should be undertaken, addressing the gaps in our knowledge of mobility paradigms so that a comprehensive ethical analysis can be undertaken. 


\section{References}

[1] Timberg, C. Riding too close for comfort. The Guardian Weekly: September 2-8, 2005.

[2] Hare, R.M. Sorting Out Ethics, Oxford University Press: Oxford, 1997.

[3] Singer, P. How are we to live? Ethics in an age of self-interest, Random House Australia: Milson Point, 1993.

[4] Wachs, M. Introduction. Ethics in Planning, ed. Wachs, M., Centre for Urban Policy Research: New Jersey, 1985.

[5] Bolan, R.S. The structure of ethical choice in planning practice. Ethics in Planning, ed. Wachs, M., Center for Urban Policy Research: New Jersey, 1985.

[6] Khisty, C.J. and Zeitler, U. Is hypermobility a challenge for transport ethics and systemicity? Systemic Practice and Action Research, 14(5), pp. 597-601, 2001.

[7] Denmark, D. The outsiders: planning and transport disadvantage. Journal of Planning Education and Research, 17(3), pp. 231-245, 1998.

[8] Gudmundsson, H. Mobility as a policy concept. Social perspectives on mobility, ed. Thomsen, T.U., Nielsen, L.D., Gudmundssen, H., Ashgate Publishing Ltd: Aldershot, 2005.

[9] Duany, A., Plater-Zyberk, E. and Speck, J. Suburban Nation: The Rise of Sprawl and the Decline of the American Dream, North Point Press: New York, 2000.

[10] Newman, P. and Kenworthy, J.R. Sustainability and Cities: Overcoming Automobile Dependence, Island Press: Washington, 1999.

[11] Squires, G.D. Urban Sprawl: Causes, Consequences and Policy Responses, The Urban Institute Press: Washington, DC, 2002.

[12] Crawford, J.H. Carfree Cities, International Books: Utrecht, 2000.

[13] Carley, M. Settlement trends and the crisis of automobility. Futures, 24(3), pp. 206-218, 1992.

[14] Nyberg, F., Gustavsson, P., Jarup, L., Bellander, T., Berglind, N. and Jakobsson, R. Urban air pollution and lung cancer in Stockholm. Epidemiology, 11(5), pp. 487-495, 2000.

[15] Frank, L.D., Andresen, M.A. and Schmid, T.L. Obesity relationships with community design, physical activity, and time spent in cars. American Journal of Preventive Medicine, 27(2), pp. 87-96, 2004.

[16] Lopez, R. Urban sprawl and risk for being overweight or obese. American Journal of Public Health, 94(9), pp. 1574-1579, 2004.

[17] Gee, G.C. and Takeuchi, D.T. Traffic stress, vehicular burden and wellbeing: a multilevel analysis. Social Science \& Medicine, 59(2), pp. 405414, 2004.

[18] Beckmann, J. Automobility - a social problem and theoretical concept. Environment and Planning D: Society and Space, 19(5), pp. 593-607, 1999.

[19] Harvey, D. Social Justice and the City, Edward Arnold: London, 1973. 
[20] Low, N.P. and Gleeson, B.J. Ecosocialization or countermodernization? Reviewing the shifting 'storylines' of transport planning. International Journal of Urban and Regional Research, 25(4), pp. 784-803, 2001.

[21] Nielsen, L.D. Reflexive mobility - a critical and action oriented perspective on transport research. Social perspectives on mobility, ed. Thomsen, T.U., Nielsen, L.D., Gudmundssen, H., Ashgate Publishing Ltd: Aldershot, 2005.

[22] Szyliowicz, J.S. Decision-making, intermodal transportation, and sustainable mobility: towards a new paradigm. International Social Science Journal, 55(176), pp. 185-197, 2003.

[23] Giesler, N.L. Ethics: Alternatives and Issues, Zondervan Publishing House: Michigan, 1971.

[24] Singer, P. Ethics, Oxford University Press: Oxford, 1994.

[25] Aristotle. Nicomachean Ethics, Books I.4-5, 7-8, II.6-7, 9. Powerful Ideas: Perspectives on the Good Society, ed. Webb, J.M., The Cranlana Programme: North Armadale, 2002.

[26] Grayling, T. Social Justice in an Upwardly Mobile Society. Sustainability and Social Justice, ed. Foley, J., Institute for Public Policy Research: London, 2004.

[27] Rawls, J. A Theory of Justice, Clarendon Press: Oxford, 1972.

[28] Burr, J.R. and Goldinger, M. Philosophy and Contemporary Issues, Macmillan Publishing Co, Inc: New York, 1976.

[29] Fricker, A. The ethics of enough. Futures, 34(5), pp. 427-433, 2002.

[30] Klosterman, R.E. Foundations for normative planning. Ethics in Planning, ed. Wachs, M., Center for Urban Policy Research: New Jersey, 1985.

[31] Urry, J. The 'system' of automobility. Theory, Culture \& Society, 21(4/5), pp. 25-39, 2004. 